\title{
Novel Process Approach for in-situ Insertion of Functional Elements in RTM-Applications
}

\author{
Mathias Bobbert ${ }^{1}$, Florian Augethaler ${ }^{1}$, Zheng Wang ${ }^{2}$, Thomas Tröster $^{2} \&$ Gerson Meschut $^{1}$ \\ ${ }^{1}$ Laboratory for Material and Joining Technology (LWF), Paderborn University, Paderborn, Germany \\ ${ }^{2}$ Chair for Automative Lightweight Design (LiA), Paderborn University, Paderborn, Germany \\ Correspondence: Mathias Bobbert, Laboratory for material and joining technology (LWF), Paderborn University, \\ Pohlweg 47-49, 33098 Paderborn, Germany. Tel: 495-251-603-035. E-mail: mathias.bobbert@lwf.upb.de
}

Received: October 8, 2016

Accepted: October 26, 2016

Online Published: November 18, 2016

doi:10.5539/jmsr.v6n1p15

URL: http://dx.doi.org/10.5539/jmsr.v6n1p15

\begin{abstract}
Lightweight design in vehicles leads to an increasing use of fibre-reinforced-plastics (FRP). To ensure the possibility of detachable joints in those constructions specific joining technologies have to be developed. Available technologies are not suitable for mass production or are leading to damage in the FRP. The aim of this paper is to show the possibilities and the general feasibility of a new process approach for the application of functional elements in FRP or hybrid materials during resin transfer moulding (RTM) processes. Therefore the movement of the RTM-tool-punch is utilised to produce an interlock between the splay stud and the fibres of the non-consolidated preform. This enables the application of the elements during the RTM-process. The resin infusion leads to the consolidation of the CFRP and a further fixation of the splay stud. Pull-out-tests as well as torsion tests are showing the mechanical performance of the joints.
\end{abstract}

Keywords: hybrid structures, inserts, functional elements, RTM-process, CFRP

\section{Introduction}

In the course of progressive developments to reduce the mass of vehicles, fibre-reinforced-plastics and hybrid materials getting increasingly important as a lightweight construction material for the body in modern cars. For use in large scale productions an efficient joining method is needed to realise detachable screw connections for attachments in the assembly line. In the mass production of conventional metal bodies weld studs / nuts and mechanically set functional elements have been established for realizing releasable connections. Such support threads can be found in all areas with thin sheets where a screw connection with additional components is needed (Grandt, 1998). For example 959 functional elements are located in the Mercedes-Benz E-Class W212 series for applications as cable-clamps, pipe supports, mounting cover and liquid containers (Hahn \& Westhoff, 2015). In contrast to the thermally inserted functional elements like welding studs or welding nuts, mechanical functional elements provide a wide range of applications inclusive non-metal materials contingent on a universal function principle (Müller, 1992; Heimlich, 2008). They are therefore also suitable for use in CFRP components. Nevertheless, the related piercing process is problematic for composite materials. Machined introduced holes, e.g. by means of circular milling, constitute a relatively gentle processing method thereby, but always mean an additional process step. A direct joint is achieved by self-piercing functional elements, but lead through the shear cutting process to local material failures like delaminations of the layer structure. Despite of the efficient procedure the components are weakened and the residual compressive strength in particular of the CFRP is reduced (Meschut et al., 2015). Moreover the deformation of the CFRP during riveting causes similar damage due to the low ductility. Based on the viscoelastic properties of the matrix system, it may further come to reduction of the clamping forces of the functional element by creeping, so that a stable anchorage in the CFRP cannot be guaranteed in the long term.

Furthermore adhesive based functional elements are available for composite applications and in use in BMW series i3 and i8 for example, see Figure 1. The use of these adhesive studs requires an elaborate surface pre-treatment, a complicated introducing process and is restricted to lightly loaded points as the forces cannot be transmitted directly into the fibres. 


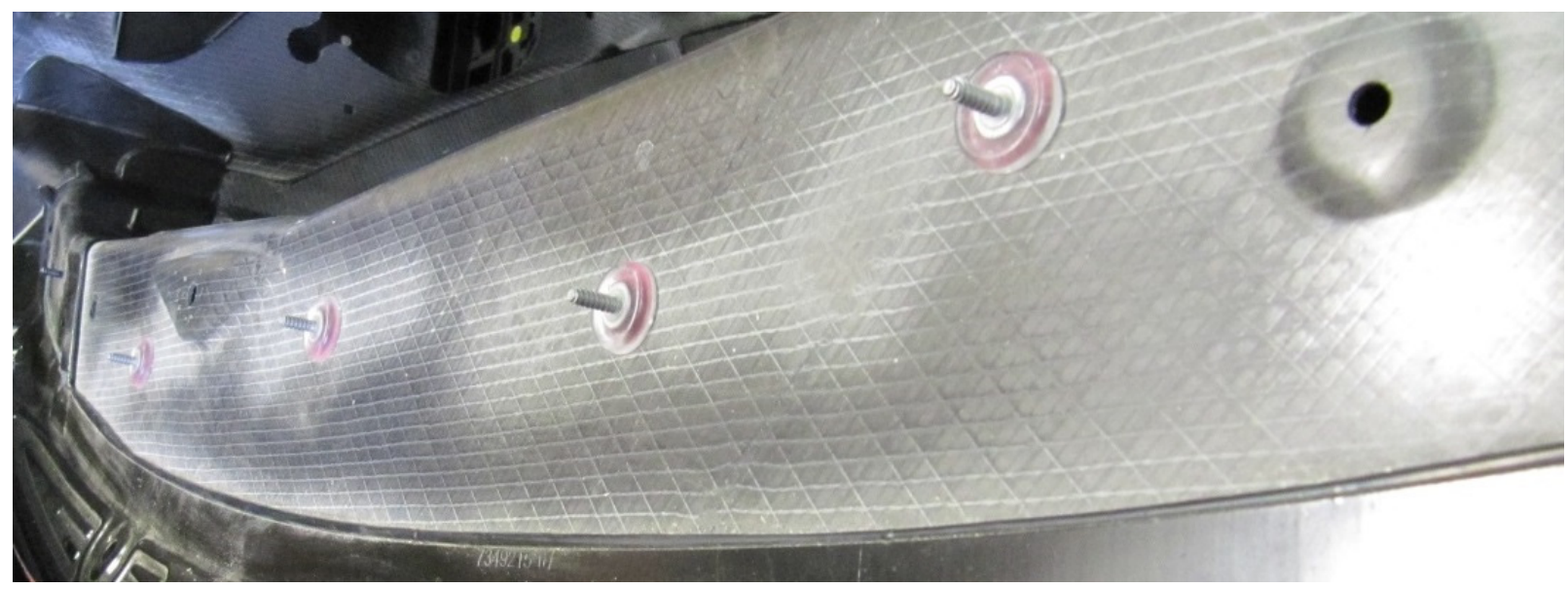

Figure 1. Dashboard carrier of a BMW i3 body in white with adhesive studs

While an element insertion in metal sheets is favoured in the press shop for reasons of efficiency, this method is not possible with CFRP components, as these do not exist in a consolidated state at the closing of the pressing tools. Admittedly various systems exist for this purpose. Currently they are laid between the fibre layers stitched with them or placed on the laminate and bonded by the matrix system (Schürmann, 2007). However, these variants are only suitable for the time-consuming manual lamination process and thus for small batch series.

This results in the development of a novel functional element for applications in FRP components that can be set in the non-consolidated part during the RTM process. Additionally process steps and damage of the composite can be avoided. Currently, there is no possibility to integrate functional elements in the series production of CFRP components in the RTM process. Especially the anchoring of the functional element to the reinforcing fibres at the press stroke and suitable sealing against resin still remains a challenge. Furthermore the closing of the RTM tools, flexibility of the element positioning regardless of the location in the top and bottom mould push the development of this innovative technology. This paper presents a suitable functional element for the described application, the associated receiving tools and the insertion process. Furthermore the mechanical performance is evaluated by pull-out and torsion tests.

\section{Method}

\subsection{Splay-Stud-Process}

To attach studs or other functional elements to a CFRP-component, the closing step of the RTM press can be utilised. Therefore, modifications to established studs, which are applied during the stacking or preforming step or after the CFRP-consolidation, have to be made. Studs which are applied after the curing of the matrix by drilling holes or cutting processes damage the composite, e.g. by delamination. An application before consolidation avoids damage. This leads to the requirement of a process with small manipulations to the fibres architecture. Due to the resin infusion gaps or other geometrical inhomogeneities, which grow during the shift, can be closed. To fulfil these requirements:

- Insertion during the closing of the RTM-tool and

\section{- Minimization of damage in the CFRP fibres}

a novel process (Figure 2) with an innovative type of functional element (Figure 4) has been developed. This consists of a threaded stud, a force transmission support and a shell. The process can also be used for CFRP-steel-hybrids.

Within the first step the attachment bushing is loaded with the splay stud. Furthermore the release agent has to be applied and the preform can be positioned on the RTM-tool. In the second step the RTM-tool starts to be closed and the splay stud touches the preform. At this point the splay element braces on the residual fibre layers and the fibres are allocated locally. Through the compression, the stud shapes four shanks which are bended and splayed sideways and dip between the fibre layers. Therefore, the splay element is pushed inside the semitubular shell and separates it in four shanks. No die is needed for this procedure. Because of this, elaborate tool adjustments are unnecessary. When the end position of the RTM-tool is reached, the forming process of the splay stud ends and an interlock between the overhead 2-4 fibre layers and the splayed shanks is generated. To protect the thread against contamination of the low-viscous resin, the studs are pushed into sealings in the bushing during the complete 
process. After that, in the 4th step, the resin is infused and cured. The infusion and curing of the resin results in additional adhesive bonding between the stud and the CFRP component. During the opening step of the RTM-tool the stud is demoulded from the attachment bushing. The attachment of the stud is completed. This new process depicts a significant improvement of the in (Koch et al., 2016) described process.

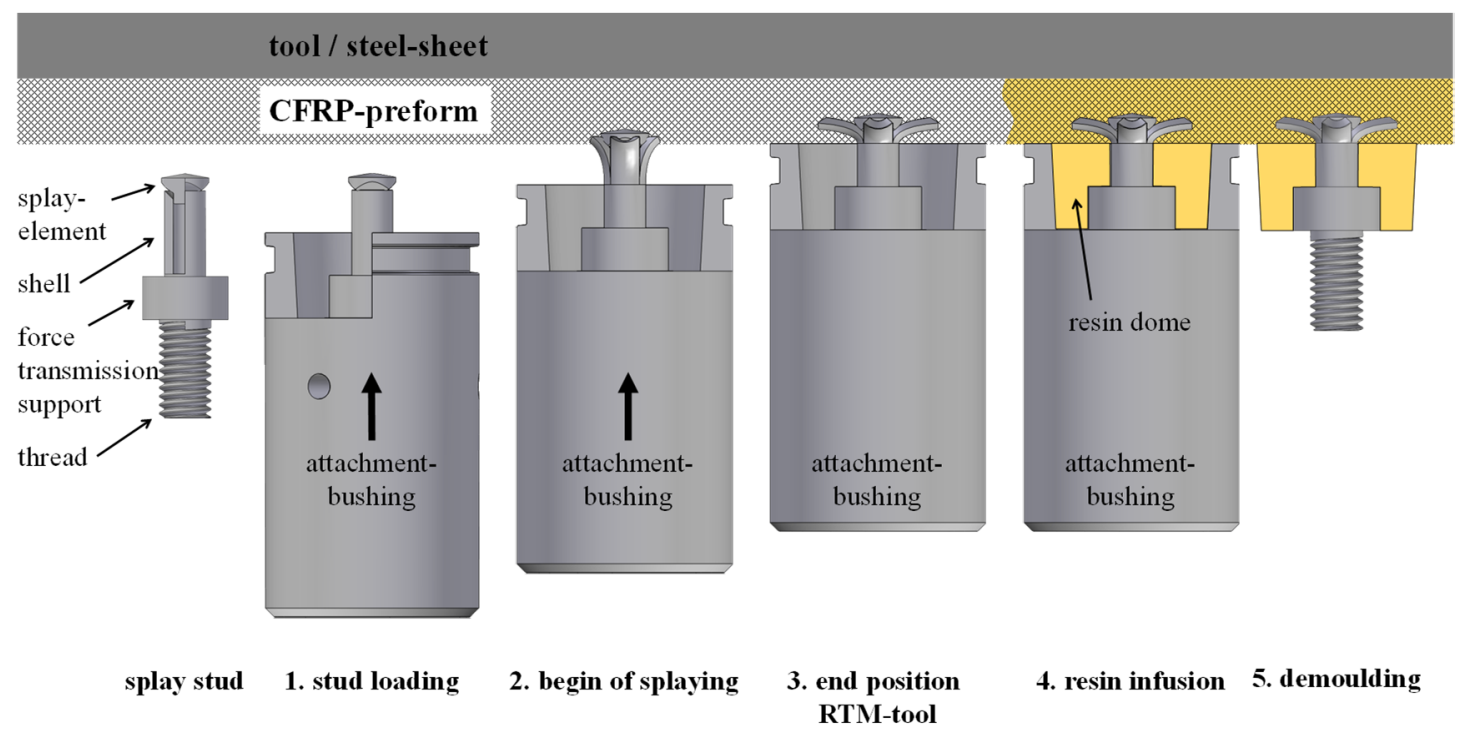

Figure 2. Principle process of the in-situ insertion of splay-studs

\subsection{Tooling Concept}

The current experimental setup consists of a planar RTM-tool with four implemented attachment bushings (Figure 3). The attachment bushings are designed for adaption to every kind of RTM-tool. Requirement is a vertical closing step and an area with a planar tool surface. Therefore a blind hole is positioned in the RTM-tool between the channels for the heating cartridges. A chamfer supports the insertion of the bushing into the hole. The bushing is fastened to the tool via screwing. To seal the gap between the RTM-tool and the bushing a silicone ring is used. The sealing material is chosen due to the low adhesion to the used resin.

The inner shape of the attachment bushing forms a defined cavity with a draft angle which will be filled with resin in the impregnation process and defines the shape of the resin dome. In the centre of this cavity the seating for the stud is located. The stud is placed in a slot and locked due to a lug. Therefore small steel balls are inserted in radial holes followed by prestressed springs and setscrews. They fix and centre the functional elements. To ensure the sealing of the thread against contamination of the low viscous resin the contact between the sealing ring and the stud has to be uphold through the whole process. The process force is transmitted through the ring until a defined compression of the sealing is reached. The force transmission support passes the residual process force directly from the bushing to the element, to avoid damage of the sealing. The sealing rings are located close to the outer diameter of the stud, to minimize the contaminated areas by resin. The depicted bushing is an advanced version of the in (Wang et al., 2016) described attachment bushing.

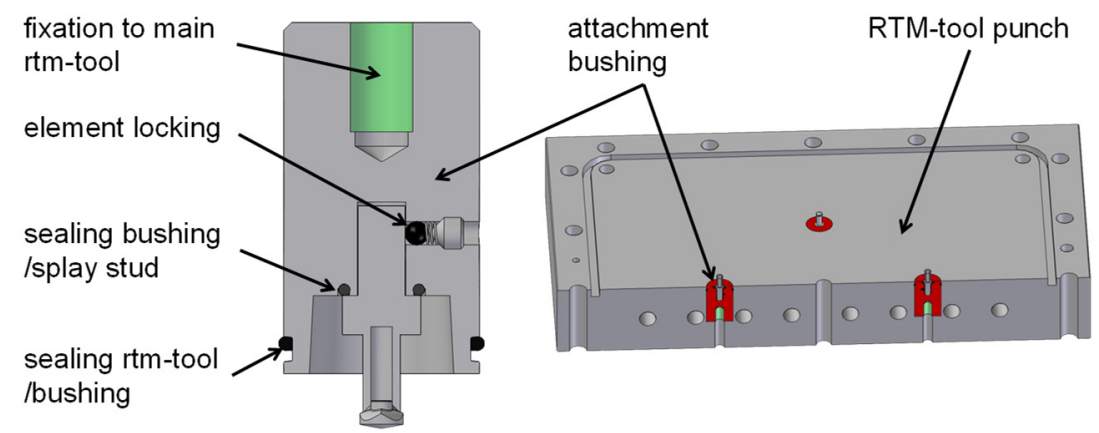

Figure 3. Attachment bushing and integration in RTM-tool 


\section{Experimental Setup}

\subsection{Materials}

The substrate materials of the test plates are consisting of $2 \mathrm{~mm}$ steel sheet and $2 \mathrm{~mm}$ CFRP with the sizes of 400 $\mathrm{mm}$ length, $400 \mathrm{~mm}$ width and a total thickness of $4 \mathrm{~mm}$. For the CFRP a 5-minutes epoxy matrix system (Momentive, 2012) and six layers carbon fibre scrim, which has a surface weight of $320 \mathrm{~g} / \mathrm{m}^{2}$ (SGL, 2016), are used. The layer structure of the bidirectional carbon fibre scrim is $(90 / 0 / 90 / 0 / 90 / 0)$. For the steel component a HC340LA alloy is used. The splay stud consists of a turn part of AlMg5 and a splay element of steel. The geometry is shown in Figure 4a. To get a higher stability of the resin-dome after injection of the resin, this area can be additionally reinforced with winded fibres according to Figure $4 \mathrm{~b}$.

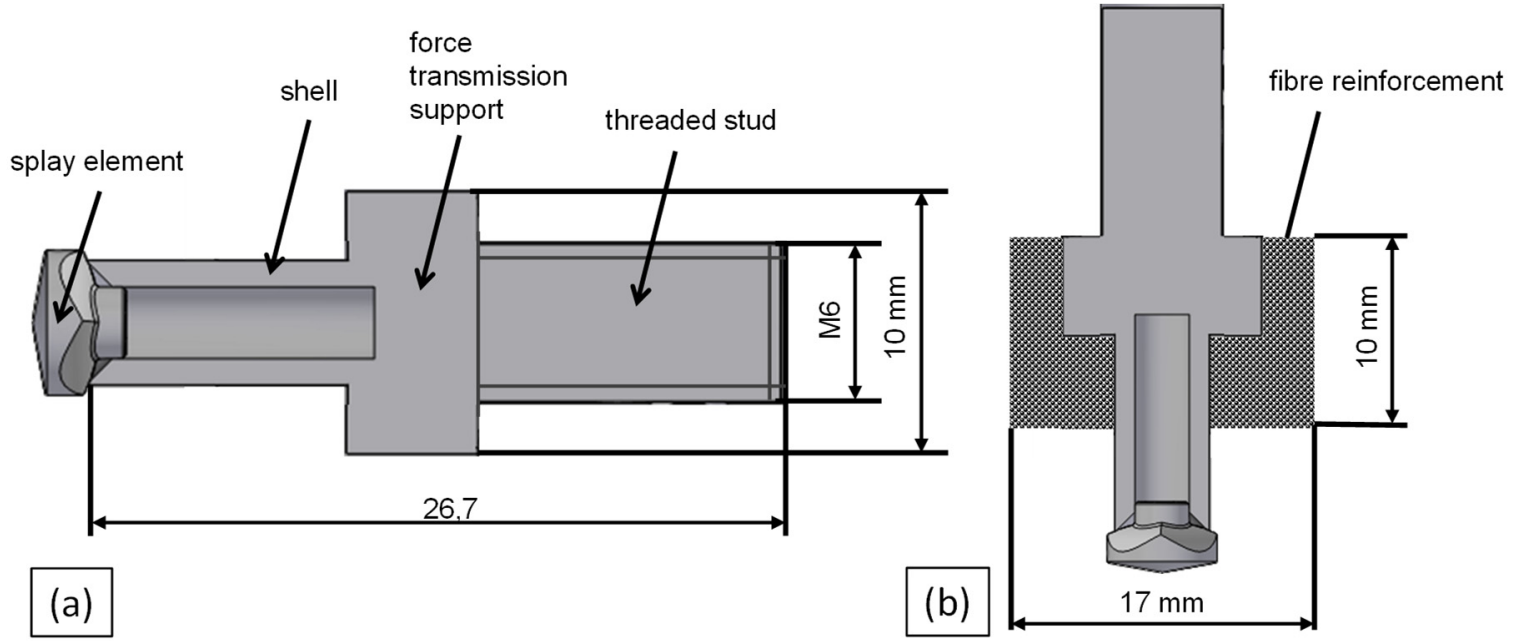

Figure 4. Geometry of the used splay stud (a) and additionally attached reinforcements (b)

\subsection{Experimental Setup for RTM-Process and Process Parameters}

The process parameters during manufacturing of the test plates are summarised in Table 1. By the RTM process the epoxy resin is injected into the mould with the temperature of $25^{\circ} \mathrm{C}$ under a constant injection pressure by 0.5 MPa for $300 \mathrm{sec}$. The mould is heated at $80^{\circ} \mathrm{C}$. The subsequent curing process takes $3600 \mathrm{sec}$. in order to achieve a good demouldability of the parts.

Table 1. Process parameters

\begin{tabular}{clll}
\hline Nomenclature & Value & Unit \\
\hline$T_{m}$ & Temperature of matrix & 25 & {$\left[{ }^{\circ} \mathrm{C}\right]$} \\
$T_{t}$ & Temperature of tool & 80 & {$\left[{ }^{\circ} \mathrm{C}\right]$} \\
$p_{i}$ & Injection pressure & 0.5 & {$[\mathrm{MPa}]$} \\
$p_{v}$ & Vacuum pressure & -0.095 & {$[\mathrm{MPa}]$} \\
$t_{i}$ & Injection time & 300 & {$[s]$} \\
$t_{c}$ & Curing time & 3600 & {$[s]$} \\
\hline
\end{tabular}

The position of the preform and the splay studs in their attachment bushings in the lower tool is shown in Figure 5. The tool is heated with heating cartridges. The thickness of the plates is defined with a $4 \mathrm{~mm}$ distance frame. The epoxy matrix is injected through four sprues into the cavity, which are located at the corners of the upper tool. The matrix impregnates the dry fibres by an annular duct und the rest flows from the centrally positioned riser into a resin trap, which is connected with a vacuum pump. 


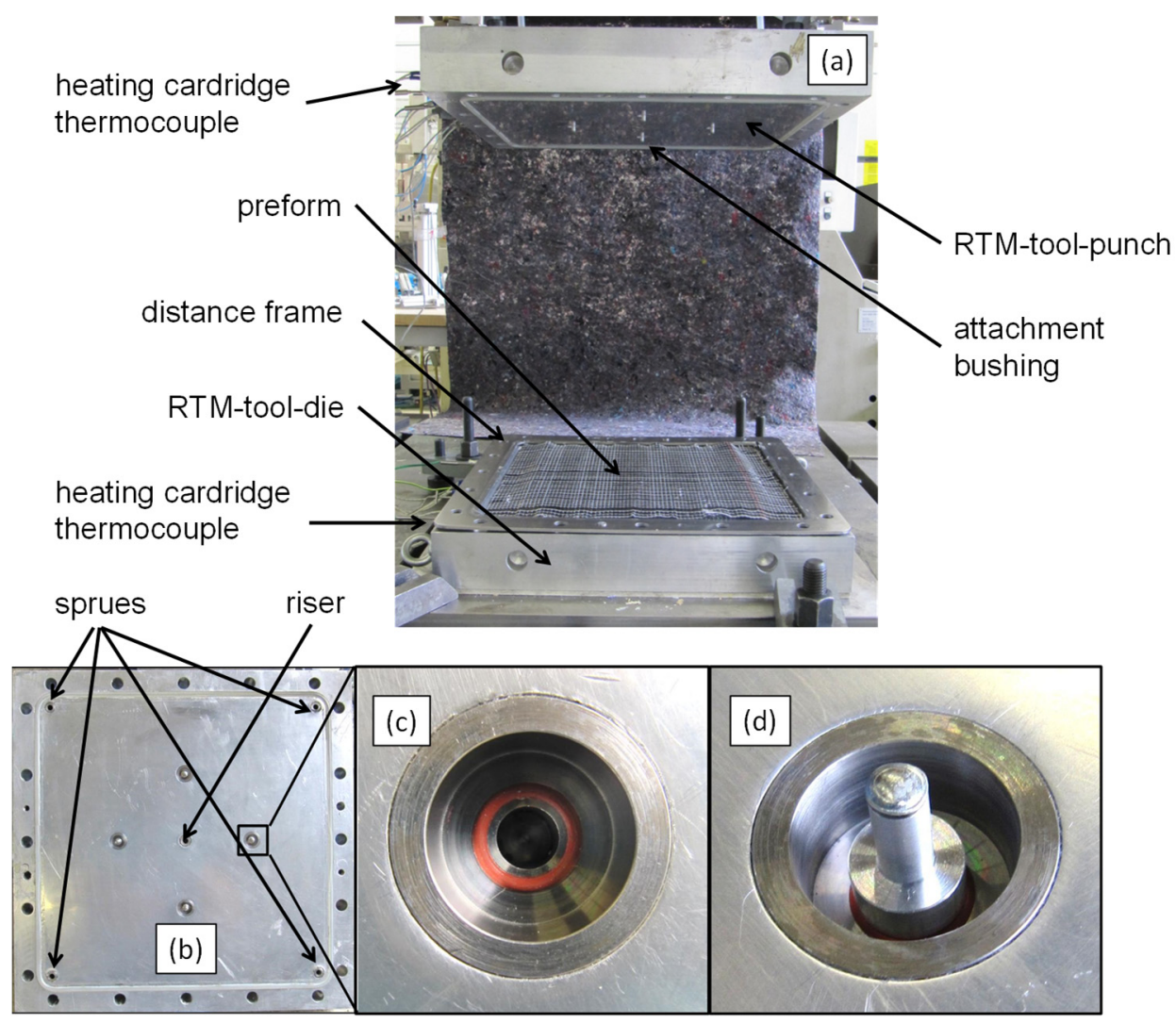

Figure 5. Experimental setup for the manufacturing of the specimen: (a) RTM-tool, (b)RTM-tool-punch with attachment bushings, (c) attachment bushing without stud, (d) attachment bushing with stud

\subsection{Experimental Setup for Testing}

In order to test the mechanical performance of the manufactured studs, specimens have to be cut out of the test plates. This allows to test each stud on his own and avoids prior damage which might occur when each of the four studs are tested when connected to one hole plate. In previous projects a specimen size of $50 \mathrm{~mm} \times 50 \mathrm{~mm}$ was suitable. To avoid damage through the cutting process a water-cooled precision cut-off machine with a low feed rate was used. The specimen is shown in Fig 6.

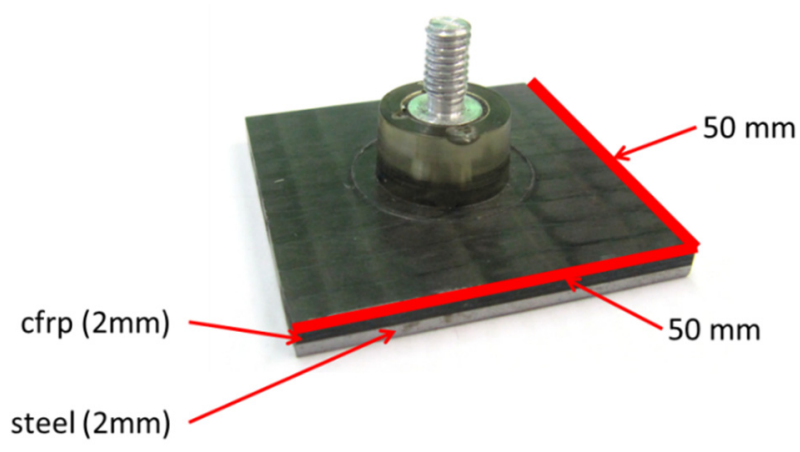

Figure 6. Specimen cut from the plate

To obtain a good overview over the mechanical performance of the studs, two different critical test scenarios were carried out. The first scenario is the pull out test. Therefore, a special test device, described in (Meschut and Süllentrop, 2014), was used which is shown in Figure 7 (a). The tests are done at the universal test machine (Zwick $\mathrm{Z}$ 100). Furthermore a torsion test was performed. To this a screw test bench (Schatz) was used. The test arrangement is shown in Figure 7 (b). 

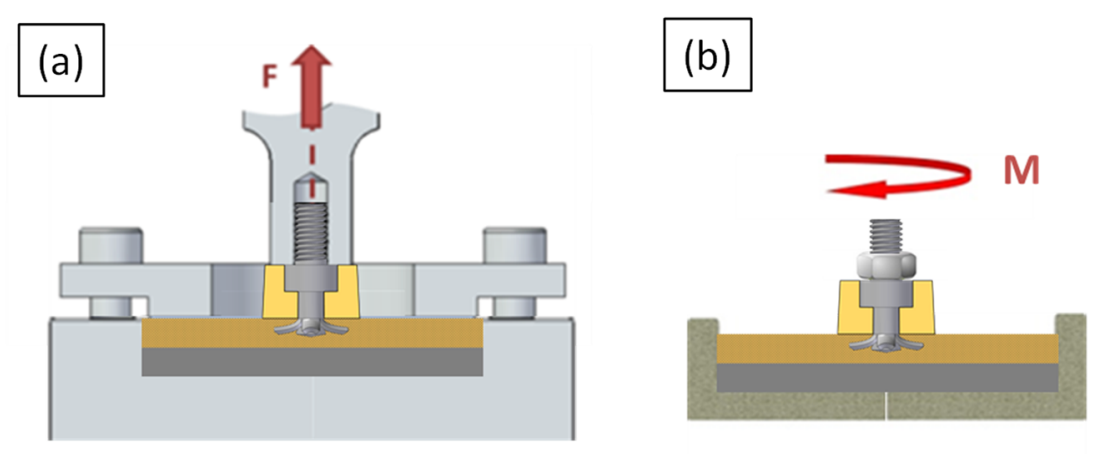

Figure 7. Experimental setup for the testing of the specimen: (a) pull out and (b) torsion

\section{Results and Discussion}

In the first step after the component manufacturing the specimen were examined concerning the achieved quality. Therefore, the joints were inspected optically and by micro sections. Figure 8 depicts a good quality of the joint (Figure 8 (a)). The micro section in Fig 8 (c) shows the required interlock between the studs and the CFRP. The four shanks are lying under the second fibre layer of the substrate material. In this micro section a small groove in the resin dome can be recognized as well. This appears due to the design of the sealing with a silicone ring, which is partially pressed in the cavity of the attachment bushing. Furthermore, some specimens show shrinkage cavity's in the top section of the joint (Figure 8 (b)). In some cases cracks in the resin dome appeared during the demoulding step. Those specimens were excluded from the testing of the joint strength.
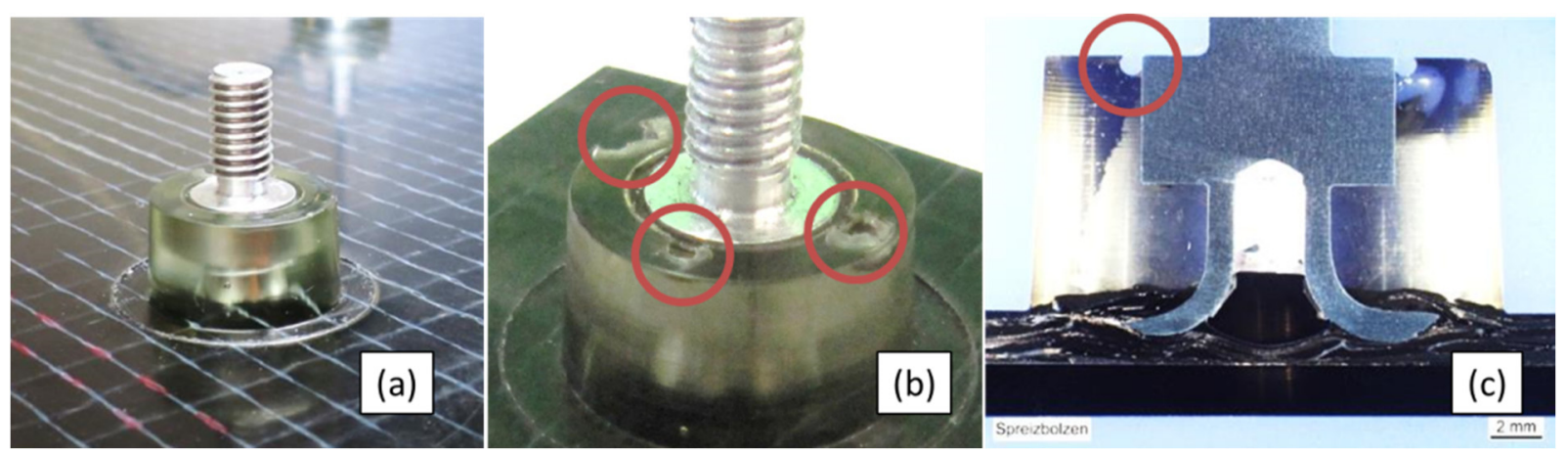

Figure 8. Photos $(a, b)$ and microsection (c) of the joints without reinforcement

The modification of the stud with a fibre-reinforced resin dome leads to an improved quality of the joint. Demoulding cracks and shrinkage cavities haven't appeared anymore.
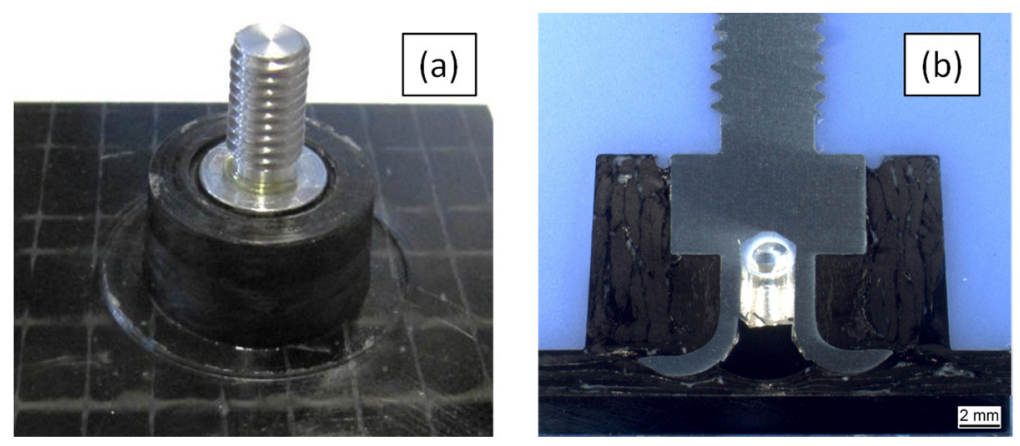

Figure 9. Photo (a) and microsection (b) of the joints with reinforcement 
According to chapter 3.3 the tests for the joint strength were carried out. The pull out behaviour of the stud without reinforced resin dome can be seen in Fig 10. The graph shows at first a linear elastic behaviour up to the maximum. The reached maximum forces averages at $2.2 \mathrm{kN}$ with a standard deviation of $0.1 \mathrm{kN}$. After the maximum a failure area with a decreasing force can be observed. The fracture behaviour was ruled by the rupture of the resin dome in the area of the connection to the CFRP-plate. Furthermore a delamination of the CFRP can be recognized which is caused by the interlock between CFRP and splay stud. On the basis of this behaviour the reinforcement of the resin dome was invented. The aim was to avoid the failure of the dome and get a higher utilisation of the stud and the interlock.

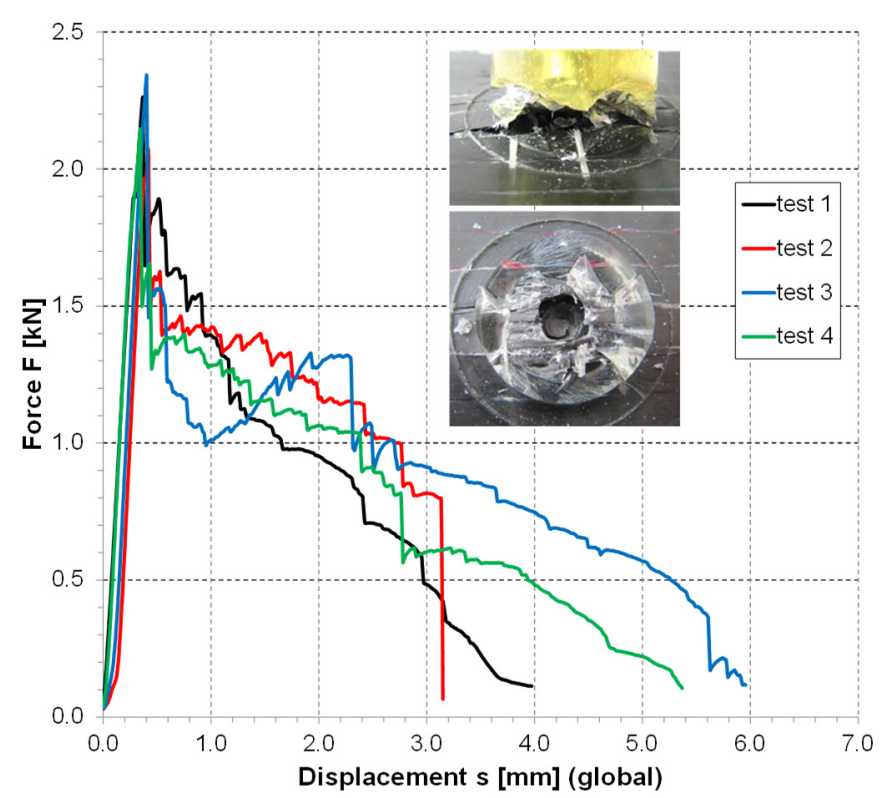

Figure 10. Experimental results of pull out tests without reinforced dome

The corresponding results to this optimisation step are shown in Figure 11. Here it can be seen that the resin dome with reinforcement stays intact during the tests. The failure appears exclusively due to delamination of the CFRP. This leads to higher maximum forces which average at $2.8 \mathrm{kN}$ with a standard deviation of $0.2 \mathrm{kN}$. The failure area which is caused by the delamination is on the same level as without reinforced resin dome.

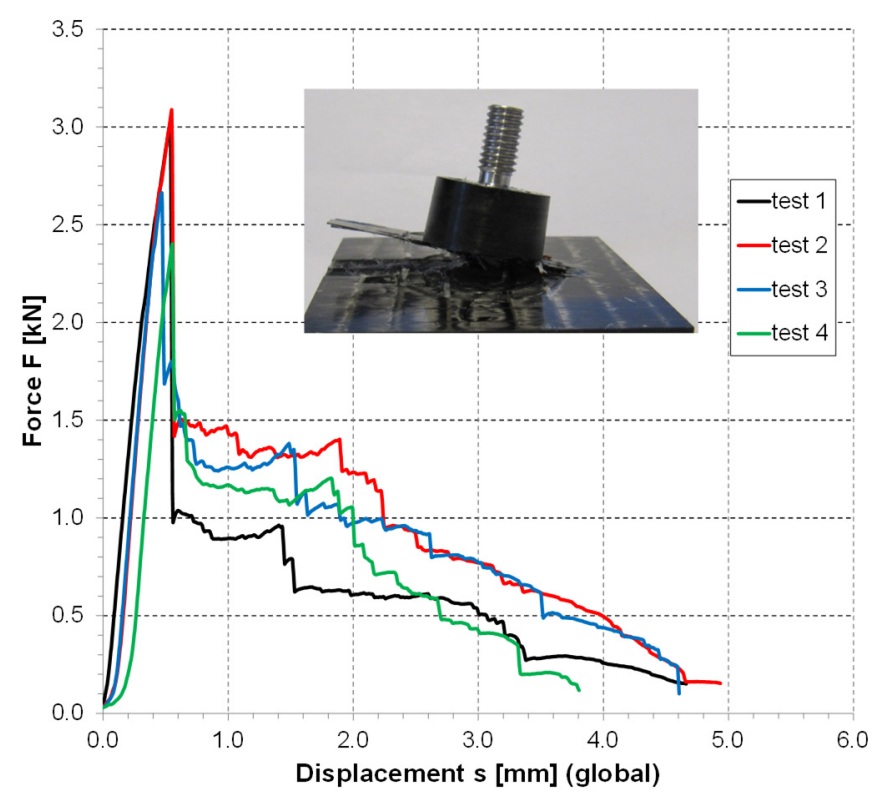

Figure 11. Experimental results of pull out tests with reinforced dome 
Furthermore, torsion tests were done. These tests showed that in this load case the strength of the aluminium splay stud was utilized completely. The failure appears only on the thread of the splay stud. The rest of the joints remains undamaged. Because of this the tests where only performed with the unreinforced stud. The maximum reached torque moments average $4.9 \mathrm{Nm}$ with a standard deviation of $0.4 \mathrm{Nm}$.

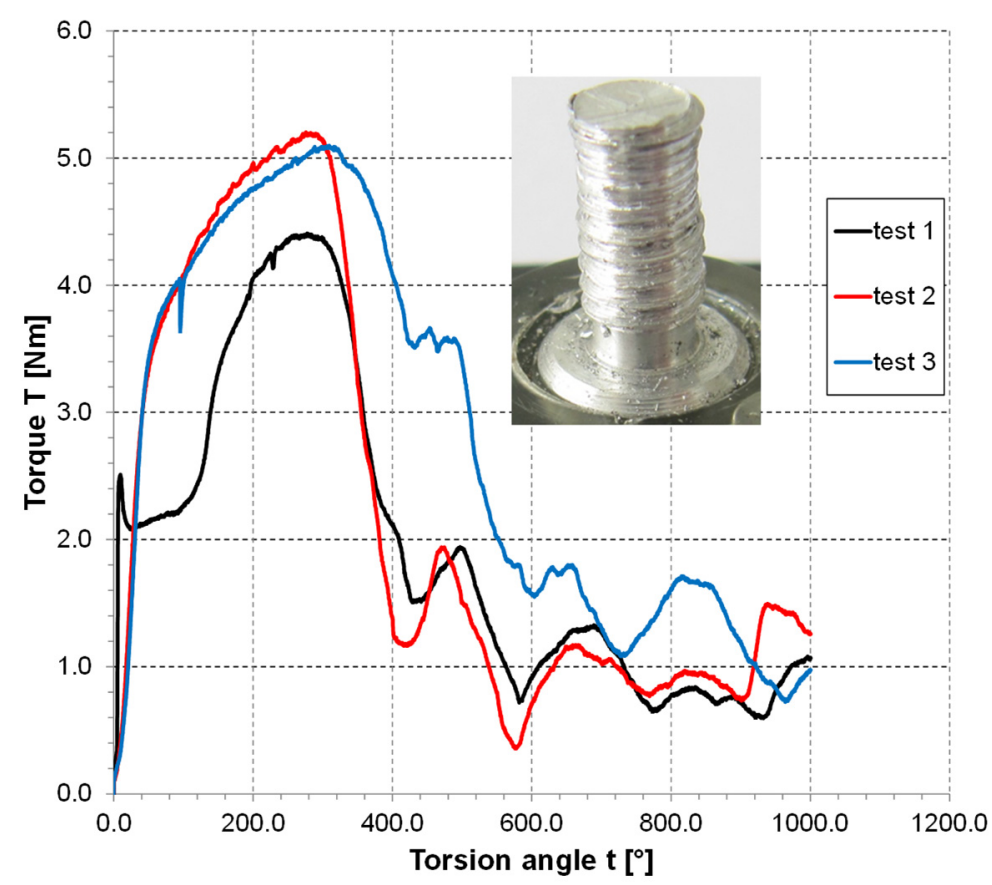

Figure 12. Experimental results of torsion tests without reinforced dome

\section{Conclusion}

A new kind of functional element for the use in CFRP and hybrid components has been described. This element can be introduced in a non-consolidated textile during the RTM process efficiently. Thus further process steps and material damages like delaminations can be avoided. With special bushings located in the RTM-tools the studs splays in the scrim under axial compression of the press stroke and forms an interlock in the CFRP. Additionally a resin dome that can be reinforced with extra winded fibres causes adhesively bonding of the stud and the component. The thread of the functional element is protected from the low-viscous resin by sealings located in the bushing. Manufactured specimens showed a good quality of the interlock and impregnation so that loading tests (pull out and torsion) have been carried out. The splay studs reached high load capabilities with partly failure of the aluminum thread which mirror the high material utilization. Further investigations will look at a better anchoring of the stud to the fibre scrim through an improved splay process or stud materials with higher strength. Further on the geometry of the resin dome will be optimised to minimize the required construction height.

\section{Acknowledgments}

This paper is based on investigations of the priority programme 1712 „Intrinsic hybrid composites for lightweight load-bearings“, which is kindly supported by the German Research Foundation (DFG).

\section{References}

Grandt, J. (1998). Blindnietgewindesysteme: Typen, Verarbeitung, Einsatzbereiche, Die Bibliothek der Technik Bd. 159; Verlag Moderne Industrie, Landsberg/Lech.

Hahn, O., \& Westhoff, D. (2015). Entwicklung und Qualifizierung eines Funktionselementes für das einseitige, vorlochfreie Fügen im Karosserierohbau, Dissertation Universität Paderborn, Shaker Verlag Aachen.

Heimlich, F. (2008). Beitrag zum Einsatz von Aluminium-Funktionselementen in Leichtbauwerkstoffen; D466 Dissertation Universität Paderborn; Shaker Verlag Aachen. 
Koch, S. F., Barfuss, D., Bobbert, M., Gross, L., Gruetzner, R., Riemer, M., ... Wang, Z. (2016). Intrinsic hybrid composites for lightweight structures: New Process Chain Approaches. Advanced Materials Research, 1140, 239-246. Trans Tech Publications. http://dx.doi.org/10.4028/www.scientific.net/AMR.1140.239

Meschut, G., \& Süllentrop, S. (2014). The use of radiation-cured adhesives on adhesive stud assembly process, Weld World, 58, 755. http://dx.doi.org/10.1007/s40194-014-0176-1

Meschut, G.; Gude, M., Geske, V., \& Augenthaler, F. (2015). Bewertung der Schädigung beim Stanznieten von Faser-Verbund-Kunststoffen, AiF-Forschungsvorhaben 17667 BG/1, EFB-Abschlussbericht.

Momentive Specialty Chemicals Inc. (2012). EPIKOTE Resin, 05475 EPIKURE Curing Agent 05443, Technical DATA Sheet, Columbus, OH, USA.

Müller, R. (1992). Schraubenverbindungen, Selbststanzende Hilfsfügeteile, Dynamisch hoch belastbar; Industrieanzeiger Heft 22.

Schürmann, H. (2007). Konstruieren mit Faser-Kunststoff-Verbunden, page 554, Springer, Berlin.

SGL. (2016). HIGH-PERFORMANCE TEXTILES. Textile Produkte aus Carbon-, Glas- oder Aramidfasern. SGL GROUP.

Wang, Z., Riemer, M., Koch, S. F., Barfuss, D., Grützner, R., Augenthaler, F., \& Schwennen, J. (2016). Intrinsic Hybrid Composites for Lightweight Structures: Tooling Technologies. Advanced Materials Research, 1140, 247-254. Trans Tech Publications. http://dx.doi.org/10.4028/www.scientific.net/AMR.1140.247

\section{Copyrights}

Copyright for this article is retained by the author(s), with first publication rights granted to the journal.

This is an open-access article distributed under the terms and conditions of the Creative Commons Attribution license (http://creativecommons.org/licenses/by/4.0/). 